\title{
Sambando na cara da sociedade: um estudo em andamento sobre a atitude e os usos linguísticos no contexto do Samba Chula de São Braz
}

\author{
Samba de roda: an ongoing study on attitude and linguistic uses in the context of Samba \\ Chula de São Braz.
}

\author{
Daisy Cordeiro* \\ Universidade do Estado da Babia \\ Salvador, Bahia, Brasil \\ Lúcia Maria de Jesus Parcero** \\ Universidade do Estado da Babia \\ Salvador, Bahia, Brasil
}

\begin{abstract}
Resumo: Este estudo é uma amostra dos achados de uma dissertação de mestrado em andamento intitulada Sambando na cara da sociedade: a resistência na atitude e nos usos linguísticos no contexto do Samba Chula de São Braz, que tem como objeto de estudo as atitudes linguísticas das sambadeiras e dos sambadores de roda do grupo Samba Chula de São Braz. Para isso, são utilizados conceitos que norteiam os estudos da Sociolinguística, com destaque especial para aqueles que põem em foco o comportamento linguístico e as crenças, valores e atitudes sobre a língua ou variantes linguísticas. O grupo foi criado oficialmente em 1995 na pequena vila de pescadores e marisqueiros de São Braz, lócus da pesquisa, comunidade que fica a cerca de 7 quilômetros do centro de Santo Amaro e é uma das comunidades reconhecidas como remanescentes de quilombo na Bahia. O contato da língua portuguesa com as línguas africanas (principalmente as dos grupos banto, kwa e iorubóide) durante os três séculos de escravidão de negros africanos traficados para o Brasil, propiciou muitas influências no português brasileiro. Com isso, essa pesquisa também objetiva buscar palavras e expressões de origem africana nos falares dos sujeitos. A metodologia a ser empregada é descritiva e segue os pressupostos da Sociolinguística Interacional e da Etnografia da Comunicação (qualitativa e interpretativa). Serão realizadas entrevistas além de observação das rodas de samba e análise das cantigas. Os critérios para a escolha dos sujeitos da pesquisa são os seguintes: serem residentes no distrito de São Braz e frequentarem os encontros do grupo de samba. O estudo deste tema é pertinente para identificar como a preferência por palavras e expressões do vocabulário afro-brasileiro, para interação no contexto do samba de roda, caracteriza a afirmação da identidade etnicorracial das sambadeiras e dos sambadores de São Braz, ou seja, como o uso da língua pode marcar seu lugar de resistência na sociedade. Além disso, esse tema se torna relevante pois visa contribuir para os estudos sociolinguísticos relacionados às atitudes linguísticas.
\end{abstract}

Palavras-chave: Samba chula. Atitudes Linguísticas. Sociolinguística Interacional.

Abstract This study is a sample of the findings of an ongoing master's thesis entitled Sambando in the Face of Society: Resistance in Attitude and Linguistic Uses in the Context of the Samba Chula de São Braz, which aims to study the linguistic attitudes of sambadeiras and of the sambadores de roda of the group Samba Chula

\footnotetext{
${ }^{*}$ Mestranda pelo Programa de Pós-Graduação em Estudo de Linguagens (PPGEL) da Universidade do Estado da Babia (UNEB) e bolsista da Coordenação de Aperfeiçoamento de Pessoal de Nível Superior/Demanda Social (CAPES/DS). E-mail: daisycordeiro@yahoo.com.br.

${ }^{* *}$ Professora orientadora: Professora titular da Universidade do Estado da Bahia (UNEB), doutora em Linguística pela Universidade Estadual de Campinas. E-mail: Imparcero@gmail.com.
} 
de São Braz. For this, concepts are used that guide the studies of Sociolinguistics, with special emphasis for those that focus on the linguistic behavior and the beliefs, values and attitudes about the language or linguistic variants. The group was officially established in 1995 in the small fishing and seafood village of São Braz, the site of the research community, which is about 7 kilometers from the center of Santo Amaro and is one of the communities recognized as remnants of quilombo in Bahia. The contact of the Portuguese language with the African languages (mainly those of the Bantu, Kwa and Yoruboid groups) during the three centuries of slavery of African blacks trafficked to Brazil, provided many influences in Brazilian Portuguese. With this, this research also aims to search for words and expressions of African origin in the subjects' speeches. The methodology to be used is descriptive and follows the assumptions of Interactional Sociolinguistics and Ethnography of Communication (qualitative and interpretive). Interviews will be conducted in addition to observing the samba wheels and analyzing the songs. The criteria for choosing the subjects of the research are the following: to be residents in the district of São Braz and to attend meetings of the samba group. The study of this theme is pertinent to identify how the preference for words and expressions of the AfroBrazilian vocabulary, for interaction in the context of samba de roda, characterizes the affirmation of the ethno-racial identity of sambadeiras and sambadores of São Braz, that is, as the use of language can mark its place of resistance in society. In addition, this theme becomes relevant because it aims to contribute to sociolinguistic studies related to linguistic attitudes.

Keywords: Samba chula. Linguistic Attitudes. Interactional Sociolinguistics

\section{INTRODUÇÃO}

Este artigo é resultado de uma pesquisa, em andamento, que tem por objetivo observar e descrever as atitudes linguísticas dos sambadores e das sambadeiras de roda do grupo Samba Chula de São Braz e identificar palavras e expressões de origem africana. A metodologia empregada sustenta-se em uma pesquisa de abordagem teórica, a qual se encontra na área da Sociolinguística, cujo respaldo teórico provém de pesquisa bibliográfica, tanto no que diz respeito à contextualização do samba chula, quanto à construção do tema deste trabalho.

Foi na pequena vila de pescadores e marisqueiros de São Braz, em Santo Amaro, que o grupo Samba Chula de São Braz foi formado e está há 22 anos se apresentando pelos palcos do mundo, divulgando sua música, sua gente, sua cultura. O samba de roda faz parte da vida dos baianos desde pelo menos o século XVIII e mantém-se vivo e contagiante até os dias atuais, dentro e fora Bahia.

O Samba Chula de São Braz é um dos principais grupos de samba da Bahia. Ao conversar com o coordenador do grupo de samba, Fernando, é possível observar que se trata de um grupo bastante aberto a pesquisas, de diferentes áreas, e que se orgulha disso. Como resultado dessa disponibilidade do grupo à pesquisa, há trabalhos acadêmicos envolvendo o grupo na área das Ciências Sociais, Cultura e Sociedade, Música, entre outros. O grupo foi fundado oficialmente em 1995 pelos irmãos Antônio Saturno, Seu Alumínio, e João Saturno, o João do Boi, mas os dois irmãos já cantavam o samba chula há muitos anos no pequeno distrito de Santo Amaro.

O estudo deste tema é pertinente para identificar como a preferência por palavras e expressões do vocabulário afro-brasileiro para interação, no contexto do samba de roda, caracteriza a afirmação da identidade etnicorracial de falantes do recôncavo, ou seja, o uso da língua para marcar seu lugar de resistência na sociedade. Além disso, esse tema se torna relevante pois visa contribuir para os estudos sociolinguísticos 
relacionados às atitudes linguísticas e às línguas africanas, que influenciaram a língua portuguesa do Brasil.

\section{O SAMBA DE RODA DO RECÔNCAVO}

Os negros africanos traficados para o Brasil em condição de escravos ao longo de três séculos trouxeram não só a força de trabalho para os cultivos de cana-de-açúcar e café e para a extração de minérios para os senhores escravocratas, mas também muito dos seus costumes, da culinária, da religiosidade, das línguas (principalmente as dos grupos banto, kwa e iorubóide) e a musicalidade. Diversos são os ritmos musicais afrobrasileiros, mas para este trabalho destacaremos o samba de roda:

O samba de roda é uma manifestação musical, coreográfica, poética e festiva, presente em todo o estado da Bahia, mas muito particularmente na região do Recôncavo. Em sua definição mínima constitui-se da reunião, que pode ser fixada no calendário ou não, de grupo de pessoas para performance de um repertório musical e coreográfico (...). (IPHAN, 2006, p. 23).

O samba de roda envolve ritmo, canto, dança com movimentos que vão dos pés até a cabeça das sambadeiras e sambadores, resultando em uma performance singular. Nerivaldo Araújo (2016, p. 107) define performance como "[...] o desempenho, a maneira de atuar, de realizar e de se comportar durante uma apresentação, por meio de toda uma poética e política [...]". Há espontaneidade, mas há toda uma liturgia no samba de roda, que embora não possua regras escritas, todos os participantes sabem como agir, como se expressar. Há ainda como elementos básicos para realização do evento samba de roda, o posicionamento dos participantes em círculo (a roda) e o acompanhamento do canto por instrumentos como pandeiro, viola, prato-e-faca.

O gênero musical samba de roda é caracterizado pela tradição oral, por ter suas canções memorizadas e transmitidas pelos mestres sambadores para os aprendizes, além de permitir improvisos, e há ainda grupos de samba que até os dias atuais não possuem registros das letras das músicas ou gravações. Segundo Katharina Döring:

A arte linguística da tradição oral se expressa pelo uso criativo da metáfora, do "sotaque", do subentendido, por vezes malicioso, brincalhão, sensual ou mesmo alertando, dando "recado", assim construindo uma prática discursiva que se alimenta da improvisação poético-musical e dos recursos performáticos e gestuais, compondo um acervo imensurável da memória e presença cultural dos filhos e das filhas da diáspora africana, perpetuado e transformado ao longo dos séculos da escravidão, repressão e pós-abolição. (DÖRING, 2016, p. 10-1).

A própria história da vila São Braz não está documentada, pouco se tem de informações oficiais acerca do local. O que se sabe é o que é contado dos mais velhos para os mais novos. Desse modo, a tradição oral está fortemente presente na cultura das sambadeiras e dos sambadores. 
No ano de 2004 o samba de roda foi reconhecido como Patrimônio Cultural Brasileiro pelo Instituto do Patrimônio Histórico e Artístico Nacional (IPHAN) e em 2005 como Patrimônio Oral e Imaterial da Humanidade pela Organização das Nações Unidas para a Educação, a Ciência e a Cultura (Unesco). O samba de roda faz parte da vida cultural de diversas cidades da Bahia. Somente no Território de Identidade ${ }^{1}$ Recôncavo há 120 grupos de samba de roda cadastrados na Associação dos Sambadores e Sambadeiras do Estado da Bahia (ASSEBA). A sede da ASSEBA é em Santo Amaro, na Casa do Samba, centro de referência para propagação da manifestação cultural além de promover treinamentos, oficinas e pesquisa.

O samba de roda tem como modalidades o samba chula e o samba corrido, sendo este muitas vezes chamado simplesmente de samba de roda. O que diferencia uma modalidade da outra é que no samba chula a dança e o canto nunca acontecem ao mesmo tempo enquanto no samba corrido ocorrem simultaneamente, e no samba chula apenas uma pessoa de cada vez samba no meio da roda, e no samba corrido várias pessoas dançam ao mesmo tempo no meio da roda.

Há no samba chula uma relação bastante estreita com o trabalho, como explica João Gilberto Mascarenhas:

O mundo do trabalho sempre teve muita importância para a configuração estética e como espaço de reprodução da chula. Como canto de labor, ela é cantada, por exemplo, nos mutirões de roça, onde o trabalhador dependia da ajuda da força de trabalho coletiva para fazer com que seu meio de produção (a terra) produzisse o necessário para sua sobrevivência. Lá ela ditava o ritmo e ajudava a distrair o árduo labor. Com a progressiva extinção dessa prática comunitária e a expansão das novas formas de organização do trabalho, esse momento de reprodução dessa expressão ficou comprometido. (MASCARENHAS, 2014, p. 115).

O Recôncavo é formado pelos municípios Cabaceiras do Paraguaçu, Cachoeira, Castro Alves, Conceição do Almeida, Cruz das Almas, Dom Macedo Costa, Governador Mangabeira, Maragogipe, Muniz Ferreira, Muritiba, Nazaré, Salinas da Margarida, Santo Amaro, Santo Antônio de Jesus, São Felipe, São Félix, Sapeaçu, Saubara e Varzedo. A área total dos municípios que integram o território alcança 5,2 mil quilômetros quadrados com população aproximada de 576,6 mil habitantes, de acordo com a Superintendência de Estudos Econômicos e Sociais da Bahia (2010). Tem como características uma marcante riqueza cultural proporcionada pelos anos de exploração de mão-de-obra escrava. Foi cenário de lutas pela independência da Bahia e concentra 420

\footnotetext{
${ }^{1}$ Classificação proposta pelo Governo do Estado da Bahia que divide o estado em 27 territórios com base no sentimento de pertencimento das comunidades. "O território é conceituado como um espaço físico, geograficamente definido, geralmente contínuo, caracterizado por critérios multidimensionais, tais como o ambiente, a economia, a sociedade, a cultura, a política e as instituições, e uma população com grupos sociais relativamente distintos, que se relacionam interna e externamente por meio de processos específicos, onde se pode distinguir um ou mais elementos que indicam identidade, coesão social, cultural e territorial" Secretaria de Planejamento da Bahia (2017).
} 
terreiros de candomblé ${ }^{2}$ segundo o Mapeamento dos Espaços de Religiões de Matrizes Africanas do Recôncavo (2012), realizado pela Secretaria de Promoção da Igualdade Racial.

São Braz fica a cerca de 9 quilômetros do centro de Santo Amaro e é uma das comunidades reconhecidas como remanescente de quilombo do Recôncavo. Após receber a certificação em 2009 pela Fundação Cultural Palmares, o distrito passa a ter direito a incentivos como apoio financeiro para a educação e manifestações culturais pelo governo federal como política de reparação. A vila possui apenas uma instituição de ensino, a escola municipal Ana Judite de Araújo Melo, com ensino fundamental regular e Educação de Jovens e Adultos (EJA) e os que desejam seguir nos estudos precisam viajar para Santo Amaro, para outras cidades próximas ou até mesmo para Salvador.

Ao visitar a aprazível vila de pescadores e marisqueiros, com aproximadamente 3 mil moradores, chamam atenção os coloridos grafites nos muros e fachadas das casas, o cheiro de dendê que vem dos restaurantes que servem os frutos do mar pescados lá mesmo e em outras regiões, a beleza do mangue da baía de Todos os Santos e, claro, a presença acolhedora dos moradores de São Braz. O samba, assim como em outros lugares de Santo Amaro, pode ser escutado em muitos estabelecimentos, em eventos festivos e espontaneamente pelas ruas de São Braz. Outro gênero musical muito marcante na vila é o reggae. Além da música, o estilo de vida jamaicano está nos cabelos de muitos moradores que exibem longos dreadlocks.

Entre os participantes dos sambas de roda, tem os que são adeptos do candomblé, organização sociorreligiosa constituída de costumes e crenças trazidos da sua origem africana e enriquecido em solo brasileiro. A casa de candomblé, também chamada de terreiro, roça ou casa de santo, "é a morada arquitetônica e sagrada das divindades, um conjunto onde agem as energias naturais, que faz a ligação física destas com os seres humanos". (KILEUY e OXAGUIÃ, 2014, p. 42). Somente na cidade de Santo Amaro há 60 terreiros.

\section{PRESSUPOSTOS TEÓRICOS}

A língua é um sistema vivo e está sujeita ao curso da história, às mudanças e transformações socioculturais. Segundo Thompson (2009, p. 173), “[...] a cultura de um grupo ou sociedade é o conjunto de crenças, costumes, ideias e valores, bem como os artefatos, objetos e instrumentos materiais, que são adquiridos pelos indivíduos enquanto membros de um grupo ou sociedade”. Língua e cultura são indissociáveis, não se pode trabalhar com um prescindindo o outro. Outrossim, a língua diz muito sobre o povo que a usa. Está diretamente ligada à identidade dos seus falantes, aos seus modos, seus costumes, pois como explica Moita Lopes (2002, p. 30), “[...] é por meio

\footnotetext{
${ }^{2}$ De acordo com Yeda Pessoa de Castro (2001, p. 82) a origem da palavra candomblé vem “(...) do banto 'kandómbilé > kandombelé', ação de rezar, pedir pela intercessão de (os deuses), derivado do verbo 'kudomba > kulomba', rezar, invocar (...)".
} 
[do] processo de construção do significado, no qual o interlocutor é crucial, que as pessoas se tornam conscientes de quem são, construindo suas identidades sociais ao agir no mundo por intermédio da linguagem". Por identidade, entendemos como "[...] algo formado, ao longo do tempo, através de processos inconscientes, e não algo inato, existente na consciência no momento do nascimento". (HALL, 2005, p. 38). Desse modo, assim como a língua é variável, está em constante transformação, a identidade também está em processo de (re)construção. Ainda segundo Hall:

A língua é um sistema social e não um sistema individual. Ela preexiste a nós. Não podemos, em qualquer sentido simples, ser seus autores. Falar uma língua não significa apenas expressar nossos pensamentos mais interiores e originais; significa também ativar a imensa gama de significados que já estão embutidos em nossa língua e em nossos sistemas culturais. (HALL, 2005, p. 40).

A Sociolinguística é o estudo da língua falada/escrita, observada, descrita e analisada em seu contexto social, isto é, em situações reais de uso. De acordo com a professora Norma Lopes:

O objeto de estudo da sociolinguística é a variação linguística, presente na fala viva em seu contexto real, não a língua apenas idealizada, objeto de outros tipos de estudo. Essa ciência estuda fatos linguísticos propriamente ditos em seus contextos e tem como preocupação explicar a variabilidade linguística e sua relação com diversos fatores (linguísticos e sociais) e a interferência dessa variação na mudança linguística. (LOPES, 2015 p. 32).

Assim, a Sociolinguística estuda fenômenos linguísticos que têm relação com fatores do tipo social, como sistemas de organização política, econômica, social e geográfica de uma sociedade; idade, raça, gênero e o nível de escolaridade; aspectos históricos e étnico-culturais; situação de interação; e o contexto externo em que ocorrem os fatos linguísticos. Conforme afirma Silvana Araújo (2013, p. 189), “(...) as variações e as mudanças linguísticas não podem ser interpretadas como resultantes de fatos exclusivamente linguísticos, pois, se pressões estruturais são importantes para ocorrerem mudanças, a sua aceitação e difusão envolvem, com certeza, fatores extralinguísticos." $\mathrm{O}$ estudo da língua como fenômeno social desfaz, portanto, a crença da homogeneidade linguística. A perspectiva sociolinguística se opõe às posições teóricas que consideram que o objeto de estudo da linguística é a língua isolada de seu contexto social.

A Sociolinguística assume o perfil de um domínio de estudos fundamentado por atividades de trabalho de campo, já que os dados linguísticos que são coletados (empíricos) não são autônomos: só fazem sentido quando considerados no contexto imediato de sua realização, de acordo com a dimensão histórica e cultural da prática humana. Assim sendo, a pesquisa sociolinguística se orienta por procedimentos metodológicos adequados ao trabalho de campo escolhido, a depender de temas e interesses do pesquisador. O campo, no caso, pode se referir a uma comunidade, que 
pode ser um local urbano ou rural, e seus contextos sociais específicos de interação verbal, como o contexto familiar, escolar, religioso, etc.

De acordo com Raquel Freitag, Marco Antonio Martins e Maria Alice Tavares (2012), os estudos sociolinguísticos são classificados em três ondas de análise. Essa categorização, proposta por Penelope Eckert, traz em cada onda uma abordagem diferente sobre a variação linguística com distintas metodologias e práticas analíticas. A primeira onda contempla os estudos iniciados por Labov, que envolvem a relação variáveis linguísticas e fatores sociais, como escolaridade, gênero/sexo, classe social, etc. A metodologia empregada na primeira onda é quantitativa. A segunda onda também é quantitativa, porém trabalha com uma perspectiva etnográfica. As pesquisas da segunda onda são realizadas em pequenas comunidades nas quais o pesquisador busca correlacionar a variação linguística a práticas sociais da comunidade. $\mathrm{Na}$ terceira onda há também o método quantitativo e tem como objetivo identificar as categorias sociais que atuam nos padrões linguísticos. A presente pesquisa está inserida nos estudos da segunda onda por analisar uma pequena comunidade e ter cunho etnográfico.

Os estudos sociolinguísticos podem trabalhar com uma abordagem macro (primeira e segunda ondas), com as comunidades de fala, e/ou micro (terceira onda), com as comunidades de prática. A pesquisa com comunidade de fala utiliza coleta padronizada (entrevista sociolinguística) enquanto com a comunidade de práticas ocorre a coleta etnográfica, com a observação dos participantes. Em uma comunidade de práticas os membros estão engajados em algum empreendimento em comum (FREITAG, 2014).

Entre os campos de estudo da Sociolinguística, temos a Variacionista, a Interacional, a Sociologia da linguagem, a Etnolinguística e a Etnografia da Comunicação. Neste trabalho, os pressupostos teórico-metodológicos utilizados são na área da Sociolinguística Interacional e da Etnografia da Comunicação.

A Sociolinguística Variacionista observa formas linguistas concorrentes e busca justificativa para essa variação tanto em uma perspectiva linguística quanto extralinguística. De acordo com Camacho (2013, p. 50), “o que a Sociolinguística Variacionista faz é correlacionar as variações existentes na expressão verbal a diferenças de natureza social entendendo cada domínio, o linguístico e o social, como fenômenos estruturados e regulares". Na Sociolinguística Variacionista, temos um método quantitativo de análise.

A Sociolinguística Interacional interessa-se pela descrição dos fenômenos de interação humana. Foi apresentada na década de 1970 pelo linguista John Joseph Gumperz. Estuda, em um grupo social, as estratégias de que o falante lança mão, as pistas de contextualização, e as inferências sobre os conteúdos compartilhados na interação verbal. Os sujeitos detêm papéis sociais, e os processos interativos de que participam constituem a realidade social. A ação mais estudada neste campo é a conversação e a sua contribuição à comunicação de significados sociais, ou seja, os usos da língua em uma situação de comunicação verbal, e as intenções, crenças e atitudes sobre estes usos. Como explica a professora Lúcia Maria Parcero (2007, p. 168) em sua 
tese de doutorado, "atitudes linguísticas consistem em idéias e julgamentos, a partir dos quais uma língua e seus falantes são avaliados". Deste modo, estudam-se também as condutas que acompanham a fala, e o conhecimento sociocultural que os sujeitos compartilham. O centro de interesse é o descobrimento das normas sociais, que são parte do ato de comunicação e que regem nossa percepção total do que é dito.

Em diversos momentos ocorre interação entre sujeitos. Interagimos com parceiros do trabalho, em casa com a família, com amigos nos momentos de lazer e até à distância, por meio das redes sociais. Há interação em toda ação humana. Tendo como referência as sambadeiras e os sambadores de roda no contexto do Samba Chula de São Braz, ocorre interação verbal e também não verbal, como quando através de uma "umbigada" se convida um participante a sambar na roda. Em uma pesquisa de caráter interacionista é preciso que o pesquisador consiga se integrar ao grupo pesquisado e interagir como um participante, pois "[não] basta trabalhar com dados surgidos da transcrição de interações orais para fazer linguística interacional”. (MONDADA, 2001, p. 62 apud MORATO, 2004, p. 336-7). Estar envolvido com a comunidade de estudo é um dos requisitos dos estudos sociolinguísticos da segunda onda.

$\mathrm{Na}$ Sociolinguística Interacional há o conceito de situação social, quando duas ou mais pessoas, relacionadas entre si de maneira particular, se comunicam sobre um tema comum em um lugar determinado (GOFFMAN, 2002). Observa-se a relação entre elas, quantas são, o grau de formalidade da situação, a previsibilidade da situação, etc. Observa-se que o estudo da situação social lança mão de índices sociais tradicionais como idade, escolaridade, gênero (sexo), etc., utilizados também na pesquisa Variacionista como fatores de análise. Assim como os níveis de formalidade do intercâmbio linguístico relacionados aos diferentes domínios de uso da língua. Cada conjunto de situações sociais constitui um âmbito de conduta sociolinguística, o domínio de uso de uma língua, como a família, a rua, o trabalho, a escola, a literatura, a imprensa, a igreja, a administração pública, etc. Não se trabalha com hipóteses, como na Sociolinguística Variacionista, e sim com questões de partida. Trata-se de uma pesquisa de metodologia qualitativa e interpretativa e não quantitativa como a Variacionista.

A respeito da Sociologia da Linguagem uma grande diferença em relação aos estudos da Sociolinguística Variacionista e da Sociolinguística Interacional é que a função social dos sujeitos no contexto social e as possíveis relações de poder que se relacionam às práticas cotidianas são fatores de análise desse tipo de pesquisa. Usa as questões da linguagem para entender a sociedade, as relações sociais. Assim como a Sociolinguística Interacional e Variacionista, os índices sociais são levados em consideração no ato da pesquisa. Não trabalha com hipóteses. O pesquisador precisa ir a campo primeiramente, não é possível antecipar questões, o campo que irá nortear a pesquisa.

A Etnografia da Comunicação "(...) pretende descrever e interpretar o comportamento linguístico no contexto cultural e (...) procura definir as funções da linguagem a partir da observação da fala e das regras sociais próprias a cada comunidade." (ALKMIM, 2001, p. 31). A concepção da Etnografia da Comunicação foi desenvolvida inicialmente por Dell Hymes e tem como fundamentos a linguística e a 
antropologia. A Etnografia da Comunicação busca compreender determinada comunidade a partir da observação da interação dos membros, dos seus eventos de fala. Essa vertente da sociolinguística é também qualitativa e exige interação do pesquisador com a comunidade.

A Etnolinguística estuda a variação linguística em relação a cultura e a forma como diferentes grupos étnicos veem o mundo. O etnolinguista estuda a maneira pela qual a percepção e a conceituação influenciam a língua e como isso está conectado com diferentes culturas e sociedades. Os precursores da Etnolinguística são Franz Boas e Bronisław Malinowski, ambos antropólogos. Segundo Pottier (1973, p. 124-5 apud DICK, 2003, p. 182), a Etnolinguística traduz "o estudo das relações entre uma língua e a visão de mundo daqueles que a falam".

$\mathrm{O}$ contato da língua portuguesa com as línguas africanas durante os três séculos de escravidão de negros africanos traficados para o Brasil, propiciou muitas influências no português brasileiro. Sobre esse contato linguístico, temos que:

De início, o número de africanos no território brasileiro era menor que o de portugueses e
índios, mas, no século XVIII, com a intensificação do comércio de escravos, em algumas
regiões eles passaram a ser maioria. Não se tem dados precisos sobre a chegada dessa
população nem sobre a língua que eles usavam aqui, se a língua geral indígena, o português
ou alguma língua geral africana. Sabe-se, no entanto, que, como as chegadas de escravos
eram sucessivas, e eles eram principalmente levados para as plantações, havia sempre
muitos deles se iniciando no português nas regiões em que eles eram inseridos. É de se
imaginar que, como nas plantações não havia muitos portugueses, o contato que os recém
transplantados tinham com a língua portuguesa trazida pelos colonizadores era muito
pouco, senão com um português transmitido por outros africanos, aprendido por eles
como segunda língua (L2). (LOPES, 2001, p. 41).

No Território de Identidade Recôncavo, região na qual está localizada a vila São Braz, havia dezenas de plantações dos grandes senhores escravocratas da Bahia. É provável que o processo de aquisição da língua portuguesa pelos africanos nessa região tenha se dado de forma deficiente, devido ao número de africanos ser maior que o de portugueses e também por causa das atividades laborais que exerciam no campo, que envolviam muito mais trabalhos braçais que interações verbais, diferente dos escravos urbanos na capital baiana, sendo alguns deles, chamados de escravos de ganho ${ }^{3}$, que vendiam produtos ou serviços e precisavam se comunicar na língua dos clientes, em português.

A respeito da influência de línguas africanas nos falares dos membros dos grupos de samba de roda, sabe-se que além das inúmeras lexias, aspectos fonológicos e características da estrutura morfossintática das línguas africanas foram incorporadas ao

\footnotetext{
3 “Os escravos de ganho faziam alguns serviços nas casas dos senhores e iam para as ruas em busca de trabalho. Alugavam seu tempo a um e a outro, e ao final do dia ou da semana deviam entregar uma determinada soma ao seu senhor ou senhora. O que passava disso os escravos embolsavam". (ALBUQUERQUE; FRAGA FILHO, 2006, p 84).
} 
português brasileiro. Como exemplos destes, podemos tomar os elencados pela etnolinguista Yeda de Castro:

- pronúncia rica em vogais do falar brasileiro (ri.ti.mox rit.mo, a.di.vo.ga.do $\mathrm{x}$ ad.vo.ga.do, pi.neu x pneu),

- tendência a marcar o plural do [sic] substantivos, quando em posição pré-nominal, apenas nos determinantes: os menino(s), as casa(s),

- o uso da dupla negação: "Não quero não".

- o emprego preferencial pela próclise: "Eu lhe disse: me dê o livro"

- o uso da preposição em com verbos de movimento. "Fui na escola",

- o uso dos pronomes dativos e acusativos com as mesmas formas; "Eu lhe vi", "Eu the conheço". (CASTRO, 2016, p. 13).

Esta pesquisa pretende ainda identificar a existência de preconceito linguístico por parte dos próprios membros dos grupos de samba de roda em relação ao uso das variantes estigmatizadas. O preconceito linguístico menospreza as variantes linguísticas do português, sejam regionais ou sociais. Além disso, prestigia o falar que se aproxima do padrão, na ideia de que a língua dita culta é uma ponte para a ascensão social. Além disso, como afirma Bourdieu (1998, p. 160-1), "a língua não é somente um instrumento de comunicação ou mesmo de conhecimento, mas um instrumento de poder. Não procuramos somente ser compreendidos mas também obedecidos, acreditados, respeitados, reconhecidos". Quem não domina a norma padrão é marginalizado e ridicularizado, pois "uma variedade linguística 'vale' o que 'valem' na sociedade os seus falantes, isto é, vale como reflexo de poder e da autoridade que eles têm nas relações econômicas e sociais" (GNERRE, 1985, p. 4). As variantes estigmatizadas são as variantes utilizadas pelas camadas mais baixas da sociedade, portanto, as camadas não prestigiadas. Quanto menos escolarizados, mais uso das variantes estigmatizadas. Uma vez que a variação linguística pressupõe a valorização social, as variantes empregadas por pessoas dessas camadas, em grande parte são estigmatizadas e o preconceito é tanto forte quanto maior for a identificação da forma com a classe discriminada.

\section{CONSIDERAÇÕES FINAIS}

Este trabalho não se encerra aqui, visto que se trata de uma pesquisa em andamento e as entrevistas e levantamento do corpus serão realizados posteriormente.

\section{REFERÊNCIAS}

ALBUQUERQUE, Wlamira R. de; FRAGA FILHO, Walter. Uma bistória do negro no Brasil. Salvador: Centro de Estudos Afro-orientais; Brasília: Fundação Cultural Palmares, 2006. 
ARAÚJO, Nerivaldo Alves. Poética oral do samba de roda das velhas margens do Velho Chico. Salvador: EDUFBA, 2016.

ARAÚJO, Silvana Silva de Farias. Sociolinguística e sócio-história do português falado em Feira de Santana-Ba. In: LOPES, Norma da Silva; BULHÕES, Lígia Pelon de Lima; CARVALHO, Cristina dos Santos (Org). Sociolinguística: estudos da variação, da mudança e da sócio-história do português brasileiro, sociolinguística paramétrica, sociofuncionalismo. Feira de Santana: UEFS Editora, 2013, p. 189-215.

BAHIA. Secretaria de Promoção da Igualdade Racial. Mapeamento dos Espaços de Religiões de Matrizes Africanas do Recôncavo. Salvador: 2012.

BAHIA. Superintendência de Estudos Econômicos e Sociais da Bahia. Estatística dos municípios baianos: Território de Identidade Recôncavo. Salvador: SEI, 2010. v. 13; 382 p. Disponível em: <http://www.zee.ba.gov.br/zee/wpcontent/uploads/2013/10/Estatistica

Municipal/est_munba_2010_rec\%C3\%B4ncavo.pdf $>$. Acesso em 25 de ago. de 2017.

BOURDIEU, P. Economia das trocas linguísticas. On: ORTIZ R. (Org). Sociologia. São Paulo: Ática, 1998, p. 156 - 183.

CAMACHO, Roberto Gomes. Da linguística formal à linguística social. São Paulo: Parábola, 2013.

CASTRO, Yeda Pessoa de. Marcas de africania no português do brasil: o legado negroafricano nas américas. Interdisciplinar-Revista de Estudos em Lingua e Literatura. São Cristóvão: UFS, v. 24, p. 11-24, 2016.

CASTRO, Yeda Pessoa de. Falares africanos na Babia: um vocabulário afro-brasileiro. Rio de Janeiro: Academia Brasileira de Letras/ Topbooks Editora, 2001.

FREITAG, Raquel Meister Ko. Covariação de uma comunidade de práticas. In: Norma da Silva Lopes; Jânia Ramos; Josane Moreira de Oliveira. (org.). Diferentes olhares sobre o português brasileiro. Feira de Santana: Editora UEFS, 2014, p. 13-30.

FREITAG, Raquel Meister Ko; MARTINS, Marco Antonio; TAVARES, Maria Alice. Bancos de dados sociolingüisticos do portugués brasileiro e os estudos de terceira onda: potencialidades e limitações. Alfa: Revista de Linguística, v. 56, n. 3, p. 917-944, 2012.

GNERRE, M. Linguagem, escrita e poder. São Paulo: Martins Fontes, 1985.

GOFFMAN, E. A situação negligenciada. In: RIBEIRO, T.; GARCEZ, P. (orgs.). Sociolinguística Interacional. São Paulo: Loyola, 2002, p. 13 - 20.

HALL, Stuart. A identidade cultural na pós-modernidade. 10. ed. Rio de Janeiro: DP\&A, 2005.

IPHAN. Samba de Roda do Recôncavo Baiano. Dossiê IPHAN 4: Ministério da Cultura, 2006.

KILEUY, Odé. OXAGUIÃ, Vera de. O candomblé bem explicado: nações Bantu, Ioruba e Fon. Marcelo Barros (org.). Rio de Janeiro: Pallas. 2014.

LOPES, Norma da Silva. A variação da concordância nominal em Feira de Santana: o efeito das comunidades de práticas. In: SOBRAL, Gilberto Nazareno Telles; LOPES, Norma da Silva; RAMOS, Jânia Martins. Linguagem, Sociedade e Discurso. São Paulo: Blucher, 2015, p. 29-44. 
LOPES, Norma da Silva. Concordancia nominal, contexto linguístico e sociedade. 2001. 408 f. Tese (Doutorado em Letras) - Universidade Federal da Bahia, Salvador, 2001.

MASCARENHAS, João Gilberto Paim. A representaşão do cotidiano no samba chula do recôncavo baiano: as letras da chula e o grupo de samba chula de São Braz. 2014. 136 f. Dissertação (Mestrado em Ciências Sociais) - Universidade Federal da Bahia, Salvador, 2014.

MOITA LOPES, Luiz Paulo da. Identidades fragmentadas: a construção discursiva de raça, gênero e sexualidade em sala de aula. Campinas: Mercado de Letras, 2002.

PARCERO, Lúcia Maria de Jesus. Fazenda Maracujá: sua gente, sua língua, suas crenças. 2007. 191 f. Tese (Doutorado em Linguística) - Universidade Estadual de Campinas. Instituto de Estudos da Linguagem, Campinas, 2007.

THOMPSON, J. B. Ideologia e cultura moderna: teoria social crítica na era dos meios de comunicação de massa. Petropólis: Vozes, 2009.

Recebido em: $12 / 06 / 2018$

Aprovado em: 23/08/2018

Publicado em: 31/12/2018 